\title{
GÉNERO, SEXUALIDADE E ATIVISMO ONLINE: UM OLHAR INTERSECIONAL PARA O PAPEL DA PARTICIPAÇÃO CÍVICA NA INTERNET POR JOVENS PORTUGUESES ${ }^{1}$
}

\author{
Daniel Cardoso* e Cristina Ponte
}

\section{Resumo}

Este artigo parte de um trabalho exploratório sobre como pessoas jovens, em Portugal, usam e pensam os novos media na construção da sua subjetividade, no campo do ativismo online em questões ligadas com a cidadania íntima. Usa-se o conceito de intersecionalidade para compreender como esta atividade é interpretada ou moralmente valorizada por pessoas em diferentes interseções de posições sociais. A partir de onze entrevistas a jovens residentes em Portugal, trabalhadas através de Análise Foucauldiana de Discurso, pretendemos aqui compreender como estas pessoas entendem os potenciais problemas deste uso dos novos media, considerando as interseções entre cidadania, género e sexualidade.

Palavras-chave: Ativismo online, género, sexualidade, jovens, qualitativo

\section{Abstract \\ Gender, Sexuality and Online Activism: An intersectional look at the role of civic engagement by portuguese youth}

This paper results from an exploratory work about how youngsters living in Portugal use and think about new media in the process of constructing their subjectivity when it comes to engaging in online activism in the area of intimate citizenship. We employ intersectionality here to understand how this activity is interpreted or morally valued by people in different intersecting social positions. From eleven interviews conducted with youngsters residing in Portugal, analyzed through Foucauldian Discourse Analysis, we seek to understand how these people comprehend the potentialities and problems that come from using new media, considering the intersections between citizenship, gender and sexuality.

Keywords: Online activism, gender, sexuality, youngsters, qualitative

\section{Résumé}

Genre, Sexualité et Activisme en Ligne: Un regard intersectionnel sur le rôle de la participation civique en ligne de la jeunesse portugaise

Cet article résulte d'un travail exploratoire sur la façon dont les jeunes vivant au Portugal utilisent et pensent les nouveaux médias dans le processus de construction de leur subjectivité, quand il s'agit de s'engager dans un activisme en ligne dans le domaine de la

* ECATI-ULHT

Faculdade de Ciências Sociais e Humanas, Universidade Nova de Lisboa, 1069-061 Lisboa, Portugal. Endereço eletrónico: danielscardoso@gmail.com

Endereço Postal: Avenida de Berna, 26-C/1069-061 Lisboa, Portugal.

** Faculdade de Ciências Sociais e Humanas, Universidade Nova de Lisboa, 1069-061 Lisboa, Portugal. Endereço eletrónico: ponte.cristina1@gmail.com

1 Apoio financeiro da FCT com a Bolsa de Doutoramento SFRH/BD/73079/2010. 
citoyenneté intime. Nous employons ici le concept de l'intersectionnalité pour comprendre comment cette activité est interprétée ou moralement valorisée par des personnes dans différentes positions sociales croisées. Sur la base de onze entretiens menées avec des jeunes résidant au Portugal, analysés à travers l'Analyse Foucauldienne du Discours, nous cherchons à comprendre comment ces personnes comprennent les potentialités et les problèmes liés à l'utilisation des nouveaux médias, compte tenu des intersections entre citoyenneté, genre et sexualité.

Mots-clés: Activisme en ligne, genre, sexualité, jeunesse, qualitatif

\section{Introdução}

Este artigo resulta de um trabalho exploratório que procura entender, junto de pessoas jovens em Portugal, como é que os usos e as representações sociais em torno dos novos media se refletem na construção da subjetividade. Iremos aqui focar especificamente o caso do ativismo online sobre questões de cidadania íntima (Plummer 1994), e as diferentes formas como este é interpretado ou moralmente valorizado por pessoas em diferentes intersecções de posições sociais. Isto implica pensar em diferentes formas e significados de ativismo online, mas também compreender como é que diferentes pessoas - quer pratiquem ou não ativismo online - encaram estas práticas.

A partir de entrevistas a onze jovens que se voluntariaram para serem questionadas e questionados sobre os seus usos da internet, e as suas perceções sobre esses mesmos usos, pretendemos aqui compreender como as potencialidades e os problemas que podem advir do uso dos novos media para a prática de ativismo online são entendidos por estas pessoas. Ademais: que papel mediador têm o género e a sexualidade nestas perceções e atividades?

As pessoas jovens em Portugal, onde o trabalho decorreu, gozam de um alto grau de acesso às novas tecnologias. De acordo com o Instituto Nacional de Estatística, 98\% de jovens entre os 16 e os 24 anos dispõem de acesso à internet. Assim, esta pesquisa exploratória tem como contexto uma sociedade bastante info-incluída, ainda que marcada pelas descontinuidades de uma modernidade tardia (Ponte 2012).

Este artigo está estruturado em três partes: uma primeira exploração teórica sobre intersecionalidade, participação cívica e novos media, uma seção metodológica que dará conta dos passos seguidos durante o trabalho de campo e posterior análise, e uma apresentação e discussão dos resultados apurados.

\section{Olhares intersecionais para jovens, participação cívica e novas tecnologias}

A juventude está sujeita a vários estereótipos relacionados com o seu uso das novas tecnologias. De 'nativismo digital' (especialmente proficientes no uso 
da tecnologia) a 'desinteresse político' (com os usos que fazem dos novos media a serem desconsiderados), estes estereótipos seguem frequentemente uma visão geracional, que lamenta um passado melhor perante um presente inferior. Porém, como afirmam Banaji e Buckingham $(2013,5)$, não é tanto que as pessoas jovens se tenham afastado do campo da política, mas sim que a política formal se mantém afastada dos assuntos que interessam a jovens, criando uma cidadania de segunda classe, mesmo quando a investigação a nível internacional mostra que existe, nas novas gerações, um nível de participação elevado. Esta participação elevada tende a focar-se em questões micropolíticas - as que mais tendem a ser desconsideradas pela política formal.

Nico Carpentier (2015) distingue diferentes formas de envolvimento no espaço público: acesso, interação e participação. O primeiro termo tem que ver com a presença, o segundo com relações de mediação e contacto, e o terceiro com a prática ativa de tomadas de decisão. É esta última forma, de acordo com Carpentier, que constitui a mais importante, na medida em que é a única que se liga à capacidade de exercer poder (decisório) e portanto influenciar. Em contraponto, Maria Bakardjieva $(2009,96)$ prefere falar de «subativismo» - formas de participação cívica que implicam «decisões e ações em pequena escala, frequentemente pessoais, [...] submergidas na vida quotidiana». O mesmo é dizer que até formas de contacto que não implicam um processo mais organizado de tomada de decisões podem, ainda assim, implicar atos que têm, por detrás, agenciamento social e político por parte de quem os pratica. Estas ações não são tão visíveis, mas não é por isso que deixam de ser importantes - fazem parte do que Peter Dahlgren (2005) apelida de «culturas cívicas». As culturas cívicas são práticas de debate e troca de ideias na esfera pública, tidas de modo informal, mas indispensáveis para a saúde de qualquer sociedade democrática.

Não existe uma visão consensual sobre que tipos de comunicação (online ou não) podem constituir atividade da esfera pública (Goode e McKee 2013); do mesmo modo, nem todas as pessoas que estão ativamente na esfera pública se pensam enquanto ativistas. A autoidentificação de ativista é contestada e problemática, e isto parece ser particularmente verdade no que diz respeito à participação cívica online (Neumayer e Svensson 2014). Assim, e de forma a garantir a inclusividade e a diversidade das formas de participação cívica de pessoas jovens, inclui-se aqui como participação cívica ou ativismo plataformas como fóruns, redes sociais, blogs, e afins, mas também a participação em eventos e organizações formais.

Perceber quem participa, em que temas participa, como enquadra a sua participação - ou, pela negativa, quem não o faz - beneficia de uma visão que olhe para os posicionamentos sociais das pessoas envolvidas. Neste aspeto, o conceito de intersecionalidade é importante, uma vez que permite fazer essa reflexão de forma mais estruturada.

O conceito de intersecionalidade (Crenshaw 2008, 280) foi criado «não como uma nova e totalizante teoria identitária», mas como uma forma de compreender 
a natureza co-constitutiva de categorias sociais tratadas geralmente como sendo separadas, nomeadamente género, sexualidade, raça/etnia e classe. Crenshaw considera que só uma abordagem intersecional pode dar conta das diferenças nas experiências de opressão vividas por pessoas que só parcialmente partilham características sociais com outras. Por detrás, está a implicação de que não existe uma dimensão ontologicamente fundacional da opressão, e que todos os eixos sociais envolvem relações de poder.

Este trabalho procura mobilizar a ideia de intersecionalidade para compreender como jovens, tecnologia e participação cívica se cruzam. Tomamos aqui como parte das interseções analisadas a orientação sexual e a construção genderizada do corpo, numa tentativa de explorar dinâmicas sociais que não estão apenas ligadas ao género. Como se verá mais adiante, porém, a componente racializada do poder social está presente apenas pela sua ausência: na medida em que só pessoas brancas se voluntariaram para participar no estudo, a pertença étnica não foi discursivizada ou problematizada por quem participou nas entrevistas, reforçando assim a ideia de que a norma social não necessita de se referenciar, uma vez que é tida como o referencial absoluto. Apesar desta lacuna, consideramos que este artigo contribui para clarificar o cruzamento entre cidadania e heterossexualidade, e entre cidadania e pressupostos corporais associados à construção do género reconhecendo que estas categorias se constituem mutuamente. Usamos aqui uma perspetiva performativa sobre género e sexualidade, enquanto categorias que são construídas através de interações simbólicas e práticas corporais; enquanto, a um tempo, autoidentidades encaradas frequentemente como imanentes mas constantemente (re)produzidas pelos sujeitos (Butler 1999, 2010).

Assim, através da intersecionalidade, questionamos neste trabalho o papel que a pertença a determinados grupos sociais, em cruzamento com o uso da internet, pode ter na compreensão da importância da participação cívica online sobre cidadania íntima, nos discursos e razões sobre a (não-)participação, e em como tudo isso se liga à autoapresentação e performatividade de género e de orientação sexual, nas onze pessoas entrevistadas.

A pertinência deste trabalho justifica-se pela relevância que, de acordo com a investigação existente, a internet tem para grupos sociais discriminados em questões de cidadania íntima, em especial junto de pessoas jovens (Gray et al. 2005; Banaji e Buckingham 2013; Szulc e Dhoest 2013; Nodin, Carballo-Diéguez, e Leal 2014; Tiidenberg 2015; Cardoso 2017).

\section{Metodologia}

Este trabalho baseia-se em onze entrevistas a jovens entre os 17 e os 20 anos que se autopropuseram a falar com o primeiro autor sobre as suas experiências online em questões relacionadas com a cidadania íntima. Isto implica já que existe um processo de autosseleção por parte de quem se dispôs à entrevista. Ainda 
assim, nem todas as pessoas entrevistadas reportaram práticas de participação cívica, ainda que entendida da forma mais abrangente detalhada acima.

A angariação de participantes foi feita por bola de neve, através de redes sociais e também através da divulgação por entre três instituições que trabalham com jovens e com questões de sexualidade: a rede ex aequo (uma associação para jovens LGBTQ), a Associação para o Planeamento da Família (focada no planeamento familiar) e o Programa Escolhas (focada em intervenção social junto de jovens vulneráveis).

Todas as pessoas entrevistadas disseram ter acesso fácil à internet desde muito cedo. Como também já referido, todas as pessoas eram lidas como brancas, e nenhuma referência a outras pertenças étnicas foi feita. Todas as pessoas tinham marcadores de pertença à classe média (pais com instrução superior e/ou de profissões liberais, capacidade financeira de deslocação geográfica para estudos, frequência de ensino superior, entre outras), embora nem todas tivessem a mesma quantidade de capital disponível. Outros detalhes caracterizadores da amostra estão disponíveis na Tabela 1.

Para propósito de análise, foi pedido às pessoas que fornecessem a sua identidade de género, com um campo de resposta em branco, para permitir qualquer tipo de autoidentificação fora do espetro binário. No entanto, e tendo em conta que um dos objetivos foi compreender como é que a participação cívica online era enquadrada, não foi feita nenhuma questão sobre orientação sexual. Isto permitiu perceber como é que a questão surgia, ou não, nos testemunhos dados. Quer também dizer que nem todas as pessoas se autoidentificaram ao nível da orientação sexual.

Assim sendo, e para interpretação dos dados da Tabela 1, as pessoas que se autoidentificaram como tendo uma dada orientação sexual foram devidamente assinaladas como tal; para as restantes, foi usada a totalidade da entrevista, e das experiências que relataram, para determinar de que modo - a partir de uma visão socialmente hegemónica e normativa da categoria de orientação sexual - é que os testemunhos eram lidos, ou interpretados (i.e., uma pessoa que, dentro do sistema binário de género, só mencionasse ligações românticas ou sexuais com alguém de género diferente seria lida como heterossexual). Não se faz qualquer inferência quanto à identidade ou pluralidade das práticas para além das relatadas, mas apenas se pretende dar conta de como cada participante se construiu discursivamente no contexto da entrevista, e que papel as suas visões e práticas relatadas de participação cívica online desempenham nessa construção.

A parte do guião da entrevista que diz respeito à prática de participação cívica online pode ser consultada no Anexo 1. 
Tabela 1

Dados das pessoas entrevistadas

\begin{tabular}{|c|c|c|c|c|c|c|}
\hline 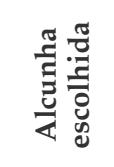 & $\frac{\tilde{T}}{\tilde{T}}$ & نัँ & $\begin{array}{l}\text { Marcadores } \\
\text { de } \\
\text { orientação } \\
\text { sexual }\end{array}$ & Ocupação & 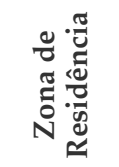 & $\begin{array}{l}\text { Notas } \\
\text { biográficas }\end{array}$ \\
\hline Íris & $\begin{array}{l}\infty \\
0 \\
\text { ప } \\
\infty \\
\sim \\
\sim\end{array}$ & हृ் & $\begin{array}{l}\text { Relata apenas } \\
\text { experiências } \\
\text { lidas como } \\
\text { heterossexuais }\end{array}$ & $\begin{array}{l}\text { Estudante } \\
\text { do Ensino } \\
\text { Superior }\end{array}$ & Lisboa & $\begin{array}{l}\text { Cresceu «na terra», num meio } \\
\text { social e geográfico mais pequeno, } \\
\text { mas encontra-se deslocada a viver } \\
\text { e estudar em Lisboa; tem uma } \\
\text { professora como mãe }\end{array}$ \\
\hline Beatriz & 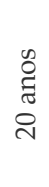 & घ્च & $\begin{array}{l}\text { Relata apenas } \\
\text { experiências } \\
\text { lidas como } \\
\text { heterossexuais }\end{array}$ & $\begin{array}{l}\text { Estudante } \\
\text { do } \\
\text { Ensino } \\
\text { Superior }\end{array}$ & Lisboa & $\begin{array}{l}\text { A mãe trabalha também com ensino } \\
\text { e investigação; antes de entrar para } \\
\text { o ensino superior, frequentou um } \\
\text { liceu católico; é originária de Lisboa, } \\
\text { onde reside ainda com os pais }\end{array}$ \\
\hline Miguel & 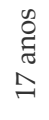 & $\stackrel{\dot{m}}{\dot{m}}$ & $\begin{array}{c}\text { Autoidentifica-se } \\
\text { como } \\
\text { homossexual }\end{array}$ & Estudante & Lisboa & $\begin{array}{c}\text { A mãe é advogada, e é originário } \\
\text { de Lisboa; não existia ainda } \\
\text { frequência de ensino superior }\end{array}$ \\
\hline Ivo & 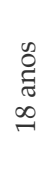 & 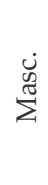 & $\begin{array}{c}\text { Afirma que } \\
\text { a questão da } \\
\text { homossexua- } \\
\text { lidade o «afeta } \\
\text { particularmente» }\end{array}$ & $\begin{array}{l}\text { Estudante } \\
\text { do Ensino } \\
\text { Superior }\end{array}$ & $\begin{array}{l}\text { Margem } \\
\text { Sul } \\
\text { (Lisboa) }\end{array}$ & $\begin{array}{l}\text { Vive na margem Sul } \\
\text { do Tejo com os pais }\end{array}$ \\
\hline Redgi & 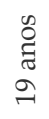 & 它 & $\begin{array}{c}\text { Autoidentifica-se } \\
\text { como gay }\end{array}$ & $\begin{array}{l}\text { Trabalhadora } \\
\text { na área da } \\
\text { restauração }\end{array}$ & Lisboa & $\begin{array}{c}\text { É oriunda de Alpiarça, mas vive } \\
\text { agora em Lisboa, em quarto } \\
\text { alugado, com mais três amigas }\end{array}$ \\
\hline Maria & $\begin{array}{l}\text { o } \\
\text { है } \\
\text { సి }\end{array}$ & घี & $\begin{array}{l}\text { Diz ter uma } \\
\text { namorada e } \\
\text { refere já ter tido } \\
\text { um namorado }\end{array}$ & $\begin{array}{l}\text { Estudante } \\
\text { do Ensino } \\
\text { Superior }\end{array}$ & $\begin{array}{l}\text { Margem } \\
\text { Sul } \\
\text { (Lisboa) }\end{array}$ & $\begin{array}{c}\text { Vive com os pais, na margem Sul } \\
\text { do Tejo }\end{array}$ \\
\hline Joana & $\begin{array}{l}\text { o } \\
\text { है } \\
\text { ڤ్ }\end{array}$ & 它 & $\begin{array}{l}\text { Relata apenas } \\
\text { experiências } \\
\text { lidas como } \\
\text { heterossexuais }\end{array}$ & $\begin{array}{l}\text { Estudante } \\
\text { do Ensino } \\
\text { Superior }\end{array}$ & Lisboa & $\begin{array}{l}\text { Vive em Lisboa com } \\
\text { o namorado }\end{array}$ \\
\hline $\begin{array}{c}\text { Subject } \\
\mathrm{A}\end{array}$ & $\begin{array}{l}\text { o } \\
\text { ¿ } \\
\text { ปे }\end{array}$ & 离 & $\begin{array}{c}\text { Autoidentifica-se } \\
\text { como } \\
\text { bissexual }\end{array}$ & $\begin{array}{l}\text { Estudante } \\
\text { do Ensino } \\
\text { Superior }\end{array}$ & Lisboa & $\begin{array}{l}\text { Viveu e cresceu numa zona rural } \\
\text { e «muito familiar» da Madeira, } \\
\text { num ambiente extremamente } \\
\text { conservador; frequentou um } \\
\text { externato e, depois, um «colégio } \\
\text { de padres»; vive na residência para } \\
\text { estudantes da sua universidade } \\
\text { durante o período de aulas }\end{array}$ \\
\hline
\end{tabular}




\begin{tabular}{|c|c|c|c|c|c|c|}
\hline Tiago & 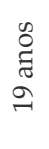 & $\begin{array}{l}\dot{u} \\
\text { J } \\
\sum\end{array}$ & $\begin{array}{l}\text { Relata apenas } \\
\text { experiências } \\
\text { lidas como } \\
\text { heterossexuais }\end{array}$ & $\begin{array}{l}\text { Trabalhador } \\
\text { na área da } \\
\text { informática }\end{array}$ & $\begin{array}{l}\text { Margem } \\
\text { Sul } \\
\text { (Lisboa) }\end{array}$ & $\begin{array}{c}\text { A mãe trabalha na área da Saúde; } \\
\text { vive com os pais na margem } \\
\text { Sul do Tejo }\end{array}$ \\
\hline Miguel & 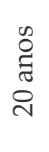 & $\begin{array}{l}\dot{y} \\
\dot{m} \\
\Sigma\end{array}$ & $\begin{array}{l}\text { Relata apenas } \\
\text { experiências } \\
\text { lidas como } \\
\text { heterossexuais }\end{array}$ & $\begin{array}{l}\text { Estudante } \\
\text { do Ensino } \\
\text { Superior }\end{array}$ & Porto & $\begin{array}{c}\text { Vive no Porto, com a mãe e as duas } \\
\text { irmãs mais novas, já que o pai está } \\
\text { emigrado }\end{array}$ \\
\hline Donald & 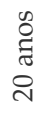 & $\begin{array}{l}\dot{y} \\
\stackrel{0}{\Sigma} \\
\sum\end{array}$ & $\begin{array}{l}\text { Autoidentifica- } \\
\text {-se como } \\
\text { homossexual }\end{array}$ & $\begin{array}{l}\text { Estudante } \\
\text { do Ensino } \\
\text { Superior }\end{array}$ & Aveiro & $\begin{array}{l}\text { É natural de São João da Madeira } \\
\text { e de um meio socialmente } \\
\text { conservador }\end{array}$ \\
\hline
\end{tabular}

Para a análise das entrevistas, foi usada uma variante da Análise Crítica do Discurso inspirada no trabalho de Foucault. A Análise Foucauldiana de Discurso (AFD) baseia-se nos conceitos e nas questões destacadas pelo autor. Para Jäger e Maier $(2010,34)$ são perguntas centrais dessa análise: «O que é conhecimento válido num certo lugar e tempo? Como é que este conhecimento surge e é transmitido? Que funções têm na constituição de sujeitos? Que consequências têm para a forma como a sociedade em geral se molda e desenvolve?». Assim, a partir da ideia de participação cívica online, procurou entender-se que sentido as pessoas entrevistadas tiravam das suas experiências, e ligá-las à criação de subjetividades (genderizadas, sexualizadas) e a discursos normativos sobre como cada subjetividade deve ser performada.

As entrevistas foram lidas com base no contexto do dispositivo de sexualidade (Foucault 1994), e prestaram particular atenção à forma como as novas tecnologias, enquanto materializações que permitem novas práticas não-discursivas e discursivas, modulam 1) as posições de sujeito, 2) os fios discursivos empregues ou 3) os agentes sociais mencionados. Na medida em que as entrevistas foram pensadas para explorar várias dinâmicas, um dos objetivos da análise foi compreender como é que esses contextos apelam a diferentes discursos e esses discursos reproduzem sistemas normativos de poder que mobilizam pressupostos sobre as interseções em análise.

\section{Heterossexualidade como privilégio}

Uma das principais diferenças ao nível da participação cívica online teve que ver com a orientação sexual.

Não se trata apenas de pessoas (lidas como) heterossexuais que não participam ou desvalorizam, ou de pessoas não-heterossexuais que o valorizam. Mesmo entre as pessoas que tinham valorizado a participação cívica, ainda que apresentando-se como heterossexuais, os seus posicionamentos revelam-se ligados a como entendem o papel da sua própria heterossexualidade, e de como a 
articulam através da desidentificação com pessoas não-heterossexuais, ou então com os próprios objetivos do ativismo LGBTQ.

As redes... pronto, como não, não me identifico com muitas coisas que estão disponíveis nos sites, por exemplo, [da rede ex aequo]. Devo dizer que vi do início ao fim, não me identifico muito com o que leio, então acabo por não pertencer... (Beatriz)

Sendo aqui um bocado bruta, a comunidade LGBT, eu tenho interesse, apoio, mas se calhar não me identifico tanto... Na medida em que não sei o que é que tenho a dar para a comunidade!, como tenho a dar para outros interesses meus. (Joana)

Várias pessoas lidas como heterossexuais usaram o mesmo conjunto de expressões - em volta da ideia de «identidade» - para justificar o seu não-envolvimento. A heterossexualidade, como significado universalizado, não precisa de se marcar a si mesma senão pela negação do seu oposto. Este posicionamento traz consigo claras escolhas políticas. Tiago vê isto como autoevidente: «quem não se identifica, claro que não vai ter o mesmo tipo de dedicação». O que aqui se apresenta é o distanciamento político face a este tema; a apresentação da heterossexualidade ligada a uma distância moral que é incluída na própria subjetividade e em que os media operam como tecnologias do self (Foucault 2000), ferramentas usadas para criar subjetividades.

Estes posicionamentos, como Beatriz ilustra, demonstram a importância do reconhecimento identitário como um aspeto problemático dentro do reconhecimento de direitos políticos e sociais. Joana enquadra a questão por via da sua ignorância, dizendo não saber o que tem para contribuir, o que pressupõe que Joana pode apenas ocupar um lugar discursivo enquanto emissora, e não, por exemplo, enquanto pessoa que pergunta, que recebe informação; a identificação, ou mesmidade, torna-se o único ponto discursivo a partir do qual é possível fazer a performance do político, ocultando o papel da heterossexualidade (enquanto sistema político normativo).

Gera-se um reforço das dicotomias e exigências colocadas sobre pessoas não-heterossexuais, na medida em que são vistas como sendo as pessoas que, 'naturalmente' terão de fazer algo. A responsabilidade por uma cidadania ativa ao nível das políticas de género e de sexualidades - a cidadania íntima de que Plummer (1994) fala - é depositada exclusivamente nos grupos sociais mais afetados pela falta de representatividade; o silêncio em torno da heterossexualidade torna-a neutra, de acordo com esta perspetiva.

Assim, pessoas lidas como heterossexuais constroem a sua heterossexualidade enquanto incapacidade de enunciação (o «não sei o que é que tenho a dar» de Joana), e na interseção entre cidadania e heterossexualidade a falha é transformada em mais-valia: ausência de responsabilidade em participação cívica. Não basta portanto olhar para a posição que estas pessoas têm sobre o assunto: é necessário fazê-la intersetar com a própria construção da sua orientação sexual. 
Outra prova disso é o modo como algumas das pessoas que se identificam como sendo LGB também se desidentificam da realização de ativismo online mas de outra forma: contrapondo-o ao ativismo presencial, e ao mesmo tempo que relatam situações em que praticaram ativismo online:

Eu prefiro pessoalmente [...]. O meu melhor amigo começou a fazer voluntariado na ILGA e eu queria-me juntar a ele, mas na altura ainda não tinha possibilidades económicas para fazer tanta viagem a Lisboa, e então acabei por não ir. (Maria)

Pá, lá está, eu não sou, não sou ativista nenhuma! E quanto menos ativista de Facebook, mesmo, não. [...] Lembro-me que pus a notícia do rapaz dos Jogos Olímpicos de Sochi, quando ele se assumiu. Pus o discurso da Ellen Page, ela a assumir-se. (Redgi)

Isto valida a forma como a identidade de 'ativista' é também tensional (Neumayer e Svensson 2014) e como o ativismo digital é visto frequentemente como uma forma secundária de ação política.

\section{A internet e a reconstrução de uma experiência corporalizada}

Outra intersecção a ter em consideração passa pela ligação entre os novos media e a experiência de construção genderizada do corpo. Dois casos identificados em entrevista permitem ilustrar esta questão de maneira a mostrar como o sistema de sexo-género (Rubin 2007) é construído com base em ocultações e desocultações de diferentes saberes, e em que jovens recorrem às novas tecnologias como parte do seu processo de construção identitária e performance de um corpo que se adapta - ou não - aos critérios do que é considerado masculino e feminino.

O primeiro caso é Subject $A$, uma jovem que cresceu na Madeira (e, pode argumentar-se, numa posição socioeconómica um pouco mais vulnerável do que a de várias das pessoas que cresceram em Lisboa ou perto dela), e cujo envolvimento com o conceito de participação cívica passou por criar uma conta na plataforma social de blogging Tumblr. Através do Tumblr, Subject A criava discussão e esclarecimento em torno de questões relacionadas com diversidade corporal, diversidade sexual, mas também práticas sexuais específicas. Ela aprendia e ensinava, criava comunidade e aliava essas conversas à partilha de imagens sexualmente explícitas, que funcionavam como trampolim para novas conversas.

É através desta ideia de participação cívica transversal a diferentes práticas, já discutidas acima (Banaji e Buckingham 2013), que compreendemos como diferentes estratégias de visibilidade e de discurso trazem ao de cima construções normativas de corporalidade, associadas ao género.

Até à criação do meu blogue, eu não fazia ideia que, tal como a maior parte das raparigas, que existiam vaginas innie e outie; não as vaginas, mas a labia. E eu achei ridículo 
[riso] durante vinte anos da minha vida, não fazer ideia. [...] E isso motivou-me ainda mais, por saber que existiam pessoas out there que não faziam ideia de como é que as coisas eram e como é que funcionavam. (Subject A)

A narrativa de Subject $A$ foca-se naquilo que não sabia e que descobriu, através das suas próprias explorações de outros blogs. O reconhecimento dessas lacunas no seu próprio conhecimento habilita um discurso de transformação (e portanto do uso dos media como tecnologias do self) que abre a hipótese de passar esse conhecimento a outras pessoas, estabelecendo o sujeito enquanto fonte de saber, que pode assim democratizar para outras pessoas esse mesmo saber.

Porém, só é possível compreender a importância do acesso e partilha deste tipo de imagens se se olhar para o contexto, e para a falta de diversidade nos modos de visibilidade de corpos considerados femininos, e diferentes feminilidades. Embora a presença de corpos lidos como femininos seja constante dentro do panorama mediático contemporâneo, a sua organização através do male gaze (Mulvey 1975) tem implicações sobre a relação estabelecida entre as representações e as pessoas supostamente representadas.

Não é exclusivamente a feminilidade que está em causa, nem tudo passa pela questão do visual - a genderização da construção do corpo tem também uma componente biologizante, tornada particularmente relevante na medida em que a epistemologia das ciências ditas exatas se configura como locus último de produção de verdade sobre o sexo-género (Rubin 2007) e sobre a sexualidade.

Eu tive um acidente, deixei de produzir testosterona. E eu quis saber qual era esse efeito, já tinha cerca de 17 anos. E queria saber o que é que isso me ia afetar [...] e eu fui ver que tipo de situação é que era esta, se havia outros casos [...]. Mais recentemente, quando eu fiz a tal operação das próteses, eu aproveitei e fiz uma coisa que 'tava para fazer já há muito tempo, que foi [a circuncisão]. [...] Fiz isso, fui ver, fui aos fóruns, da internet, ver a opinião das pessoas, se valia a pena ou não... [...] Ah, sim, ajudou-me, sim! Ajudou-me a formar uma opinião, mais concreta... e também a minha família aconselhou... realmente motivaram-me a fazer essa operação. (Miguel)

A ausência de produção de testosterona, associada à possibilidade de efeitos negativos «na minha mente, como no meu corpo»e, pela situação em questão, associada à impossibilidade de ter filhos e remoção dos testículos - ambos marcadores normativos de masculinidade e virilidade - criaram, para Miguel, um posicionamento de falante enquanto Outro. Uma das formas de lidar com a questão foi recolher informação deixada pela participação cívica de outras pessoas - onde se acrescenta, em tom utilitário ou de planeamento racional, a oportunidade da circuncisão junto da operação para colocar as próteses testiculares.

É na marcação das diferenças que se pode ler o único caso, por entre as entrevistas realizadas, em que um falante que é lido como heterossexual tem experiências de participação cívica ou envolvimento em grupos que se aproximam das que 
são apresentadas por pessoas não-heterossexuais. A preocupação com a estranheza pode ser entendida de forma dupla: é a tentativa de escapar de um lugar de enunciação marcado pela alteridade e ininteligibilidade social; é a tentativa de adquirir recursos que permitam discursivizar a própria experiência pessoal, algo que permita «uma opinião, mais concreta». Portanto, não basta considerar o lugar de Miguel enquanto homem - é preciso intersetar essa identidade com as normas de construção biologizante do que a masculinidade tem de ser, com o corpo que Miguel de facto tem, e com a injunção à proatividade que advém do seu domínio das tecnologias.

Ao fazê-lo, Miguel contorna uma perspetiva estritamente biomédica no seu processo de tomada de decisão, e refaz o seu conceito de masculinidade, refazendo também, tal como Subject $A$, a relação que tem com o seu corpo.

\section{Reflexões finais}

Enquanto trabalho qualitativo, esta investigação não pretende dar respostas sobre a preponderância de cada uma das dinâmicas identificadas, mas compreender como se processam através da análise dos relatos e discursos das pessoas jovens, entendidos numa perspetiva construcionista (Silverman 2014).

Através destas duas interseções é possível compreender que as linhas de delimitação de uma categoria de atividade online - a participação cívica - são, na verdade, mais porosas, e que as dicotomias entre físico ou virtual, participação ou não-participação, consumo e produção, não se encontram estabilizadas.

Mais do que isso, porém, estes resultados permitem compreender a fundo, como só um olhar intersecional pode explorar, a diversidade de posições possíveis, e compreender como posições de privilégio e discriminação se acumulam, se reforçam mutuamente e permitem questionar identidades enquanto unidades estanques. Não existe, nesta perspetiva, uma experiência unitária «LGBT», nem uma experiência unitária «masculina» ou «feminina», senão cruzamentos com questões de orientação sexual, género, pertença étnica, posicionamento socioeconómico e diferentes entendimentos do uso das novas tecnologias.

Como foi possível entender pela análise acima, as pessoas jovens não se limitam a participar ou não participar civicamente, nem essa participação pode ser entendida apenas pelo acesso ou falta de acesso aos recursos técnicos e de literacia necessários para essa participação (embora estes sejam, claro, fundamentais). Do mesmo modo, pertencer ou não a um grupo socialmente discriminado não determina também a validação ou não da importância do ativismo online, nem da participação ou não nele. É necessário, como aqui procurámos explorar, entender múltiplos posicionamentos em torno da orientação sexual e da expressão corporalizada do género - e de como cada uma destas coisas é construída e performada - para compreender em maior profundidade tanto a participação cívica como o papel das novas tecnologias na construção destas identidades. 
A questão da raça e etnia encontra-se presente apenas pela sua ausência. Nenhuma pessoa do estudo alguma vez abordou questões de discriminação racial. Esta lacuna mostra que as identidades acima identificadas - de heterossexualidade ou não, genderizadas e com diferentes pertenças socioeconómicas e geográficas existem apenas dentro do eixo da branquidão enquanto ponto nulo de enunciação. Não só as conceções normativas de género e sexualidade são constituídas através do binarismo de sexo-género e através da hetero-monogamia, como também são constituídas através da branquidão racial.

De facto, há um problema de sub-representação de diversidade étnica no ativismo, em Portugal, tanto em espaços digitais como fora. Estas narrativas não se localizam a si mesmas dentro da sua branquidão (ainda que algumas das pessoas entrevistadas, por exemplo, tenham participado em iniciativas com organizações que trabalham com minorias étnicas e outros grupos em situação de fragilidade social). Isto mantém, como Crenshaw (2008) identificou, eixos co-constitutivos de opressão aparentemente separados, amplificando o grau de opressão de, por exemplo, pessoas LGB ou pessoas que não sejam cismasculinas e que não sejam lidas enquanto brancas, em Portugal.

Assim, este trabalho deixa em aberto - e como desafio a mais investigação - a interseção fundamental a fazer com questões étnicas e raciais.

\section{Referências bibliográficas}

Bakardjieva, Maria. 2009. «Subactivism: Lifeworld and Politics in the Age of the Internet». The Information Society 25 (2): 91-104. doi:10.1080/01972240802701627.

Banaji, Shakuntala, e David Buckingham. 2013. The civic web: young people, the Internet and civic participation. The John D. and Catherine T. MacArthur Foundation series on digital media and learning. Cambridge, Massachusetts: The MIT Press.

Butler, Judith. 1999. Gender Trouble: Feminism and the Subversion of Identity. New York: Routledge.

Butler, Judith. 2010. «Performative Acts and Gender Constitution: An Essay in Phenomenology and Feminist Theory». Em Feminist Theory Reader: Local and Global Perspectives, editado por Carole R McCann e Seung-Kyung Kim, 419-30. New York: Routledge.

Cardoso, Daniel. 2017. «'I Sort of Knew What I Was, So I Wanted to See What Awaited Me': Portuguese LGB Youngsters and Their Situated Experiences with New Media». Em LGBTQs, Media and Culture in Europe, editado por Alexander Dhoest, Łukasz Szulc, e Bart Eeckhout, 208-23. Routledge Research in Cultural and Media Studies. Routledge.

Carpentier, Nico. 2015. «Differentiating between Access, Interaction and Participation». Conjunctions. Transdisciplinary Journal of Cultural Participation 2 (2): 7-28. doi:10.7146/ tjcp.v2i2.22915.

Crenshaw, Kimberlé Williams. 2008. «Mapping the margins: Intersectionality, identity politics and violence against Women of Color». Em The feminist philosophy reader, editado por Alison Bailey e Chris J. Cuomo, 279-309. Boston: McGraw-Hill.

Dahlgren, Peter. 2005. «The Internet, Public Spheres, and Political Communication: Dispersion and Deliberation». Political Communication 22 (2): 147-62. doi:10.1080/10584 600590933160 . 
Foucault, Michel. 1994. História da sexualidade 1: A Vontade de Saber. Lisboa: Relógio d'Água. Foucault, Michel. 2000. «Technologies of the Self». Em The essential works of Michel Foucault, 1954-1984: Ethics, editado por Paul Rabinow, 1: 223-51. Essential Works. London: Penguin.

Goode, Luke, e Alan McKee. 2013. «Conflict and seduction in the public sphere». Media, Culture \& Society 35 (1): 113-20. doi:10.1177/0163443712464565.

Gray, Nicola J., Jonathan D. Klein, Peter R. Noyce, Tracy S. Sesselberg, e Judith A. Cantrill. 2005. «Health Information-Seeking Behaviour in Adolescence: The Place of the Internet». Social Science \& Medicine 60 (7): 1467-78. doi:10.1016/j.socscimed.2004.08.010.

Jäger, Siegfried, e Florentine Maier. 2010. «Theoretical and Methodological Aspects of Foucauldian Critical Discourse Analysis and Dispositive Analysis». Em Methods of critical discourse analysis, editado por Ruth Wodak e Michael Meyer, 2nd ed., 34-61. Introducing qualitative methods. London; Thousand Oaks, California: SAGE Publications.

Mulvey, Laura. 1975. «Visual Pleasure and Narrative Cinema». Screen 16 (3): 6-18. doi:10.1093/ screen/16.3.6.

Neumayer, Christina, e Jakob Svensson. 2014. «Activism and Radical Politics in the Digital Age: Towards a Typology». Convergence: The International Journal of Research into New Media Technologies, Outubro, 1-16. doi:10.1177/1354856514553395.

Nodin, Nuno, Alex Carballo-Diéguez, e Isabel MP Leal. 2014. «Sexual Use of the Internet: Perceived Impact on MSM's Views of Self and Others». New Media \& Society 16 (5): 719-36. doi:10.1177/1461444813489508.

Plummer, Ken. 1994. Telling Sexual Stories: Power, Change and Social Worlds. New York: Routledge.

Ponte, Cristina. 2012. Crianças \& media: pesquisa internacional e contexto português do século XIX à actualidade. Lisboa: Imprensa de Ciências Sociais.

Rubin, Gayle. 2007. «Thinking Sex: Notes for a radical theory of the politics of sexuality». Em Culture, Society and Sexuality: A Reader, editado por Richard Parker e Peter Aggleton, 2. ${ }^{a}$ ed. New York: Routledge.

Silverman, David. 2014. Interpreting Qualitative Data. 5. ${ }^{\text {a }}$ ed. Los Angeles, California: SAGE Publications.

Szulc, Łukasz, e Alexander Dhoest. 2013. «The internet and sexual identity formation: Comparing Internet use before and after coming out». Communications: The European Journal of Communication Research 4 (38): 347-65. doi:10.1515/commun-2013-0021.

Tiidenberg, Katrin. 2015. «Boundaries and Conflict in a NSFW Community on Tumblr: The Meanings and Uses of Selfies». New Media E Society, Janeiro, 1-16. doi:10.1177/1461444814567984.

Daniel Cardoso. Professor Auxiliar na Universidade Lusófona de Humanidades e Tecnologias, e Professor Auxiliar Convidado na Faculdade de Ciências Sociais e Humanas da Universidade Nova de Lisboa. Tem um doutoramento em Ciências da Comunicação, e a sua investigação foca-se principalmente sobre questões de género e sexualidades, e sobre não-monogamias consensuais. O seu trabalho pode ser encontrado em www.danielscardoso.net

Cristina Ponte. Professora Associada com Agregação em Estudos dos Media e do Jornalismo na Faculdade de Ciências Sociais e Humanas da Universidade Nova de Lisboa (FCSH/NOVA). Investiga a relação entre media e gerações, com foco em crian- 
ças e jovens, desde os anos 1990, tendo vários livros e dezenas de artigos publicados. Coordena a equipa portuguesa na rede EU KIDS ONLINE, é membro da sua direção e consultora do projeto Global Kids Online, da UNICEF.

Artigo recebido em 30 de dezembro de 2016 e aceite para publicação a 20 de março de 2017. 